\title{
BIOETHICS IN THE QUALITY OF THE MEDICAL SERVICE OF GRADUATES IN LINKAGE WITH SOCIETY
}

\author{
MSC Ada María Hernández González ${ }^{1 \rrbracket}$, PHD Jorge Elias Daher Nader ${ }^{2}{ }^{\square}$ \\ ${ }^{1}$ Co-Evaluator, Manager of The Master of Bioethics, Manager of Student Welfare in The Medicine Career and \\ Professor at The University of Guayaquil Master in Bioethics, First and Second Degree of General Medicine \\ Comprehensive, Doctor of Medicine, Ecuador \\ ${ }^{2}$ Research Manager of The Obstetrics Career, Member of The Research, Postgraduate and Knowledge \\ Management Council, Associate Professor, From the University of Guayaquil, Master's in Public Health, \\ Governance, Educational Management, Ecuador
}
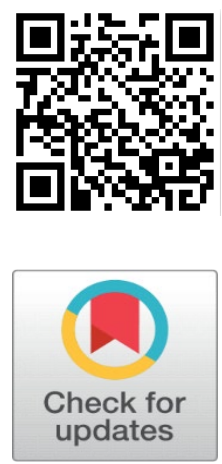

Received 07 January 2022

Accepted 17 February 2022

Published 03 March 2022

CorrespondingAuthor

Jorge Elias Daher Nader,

jdaher_nader@yahoo.es

DOI

10.29121/granthaalayah.v10.i2.2022 .4496

Funding: This research received no specific grant from any funding agency in the public, commercial, or not-for-profit sectors.

Copyright: (C) 2022 The Author(s). This is an open access article distributed under the terms of the Creative Commons Attribution License, which permits unrestricted use, distribution, and reproduction in any medium, provided the original author and source are credited.

\section{ABSTRACT}

Offering good quality in health services in our country and in the world is essential. Inculcate this importance in students and develop in them an awareness that allows them to establish a correct Doctor-Patient Relationship, based on the Universal Principles of Bioethics: Autonomy, Beneficence, Non-Maleficence and Justice. This article is the result of an investigation, which raises the importance of the quality of services and how it should be carried out by doctors graduated from the University of Guayaquil in their relationship with the Society. It highlights certain key points and requirements that the doctor must meet in order to have a satisfactory quality of service provided in the DoctorPatient relationship. Obtaining as results a guide or protocol of action, governed in the form of points that all doctors must carry out to fulfill the fundamental objective of achieving an efficient Doctor-Patient relationship and offering high Quality in Health Services. The training and professionalization of our Graduates in Health Sciences require Quality, a Rigorous, Complex, Holistic, Challenging preparation; that marks the difference between a Professional and an Amateur of Medicine.

Keywords: Bioethics, Quality, Health, Graduates, Link with Society

"Quality is the only path to growth" - Jack Welch

\section{INTRODUCTION TROUBLE}

Ensure that the Graduates provide a Quality Medical Service, in their early Link to society from the Universal Principles of Bioethics, where a guide and requirements to be taken into account will be structured, so that a correct professionalism in the Quality of the Service is achieved Doctor.

\section{PROBLEM FORMULATION}

Offer an excellent Quality of Medical Services, from a Bioethical prism, by the Graduates of the University of Guayaquil.

\section{OBJECTIVES \\ General}

- Determine the requirements for good Quality in Medical Services for graduates from a Bioethical perspective in their Link with Society. 


\section{Specifics}

- Identify the Universal Principles of Bioethics in their relationship with the requirements for Quality Medical Care

- Specify in a guide the Bioethical Requirements that Graduated Physicians must apply for Quality Care.

\section{WORK JUSTIFICATION}

It responds to the felt needs of the Community and where there must be a Methodology to offer excellent quality in Medical Services, where Graduates must have a Bioethical, Integrative and Holistic perspective; and can provide a Quality Service as Health Professionals once they graduate from Our Emblematic University of Guayaquil and constitute a Paradigm for the rest of the Health Universities.

\section{THEORIES}

Relate Bioethical knowledge, personalized to the Universal Principles with the Quality of Medical Services.

The demand by the current society of Quality Medical Services by the graduates of the University of Guayaquil

A methodological guide or action protocol for Graduated Physicians is required, which meets the needs for a Quality Service in the Community.

\section{THEORETICAL FRAMEWORK}

Since the 1970s, with Van Rensselaer Potter, a new era of Health projection began, relating the knowledge of Life Sciences with modern and contemporary problems, highlighting the recovery of ecosystems, the integration of man and nature, styles, modes and healthy conditions and Quality in Health Services.

The University of Guayaquil, being one of the most emblematic in Ecuador, annually graduates more than 100 students in the Faculty of Medical Sciences in the Medicine Career, who have the necessary knowledge to offer quality services. Current graduates have, within their professional competence, knowledge of Bioethics that allows them to make the right decisions and always in favour of the Quality of Life of patients, with humanism and dignity; knowing how to accompany patients until their last days. Responding to basic health needs that are evidenced in its Link with Society.

Offering good quality in health services in our country is essential. Inculcate this importance in students and develop in them an awareness that allows them to establish a correct Doctor-Patient Relationship, always based on the Universal Principles of Bioethics: autonomy, beneficence, non-maleficence, and justice.

Different concepts were studied in which the Royal Academy of the Spanish Language stood out, where "Quality" is defined as the "Property or set of properties inherent to something, which allow judging its value" (Dictionary of the Spanish language, 23rd ed., online).

One of the most accurate definitions of the Service Quality concept was introduced by Donabedian (1980) and defined as: "That type of care in which it is expected to maximize a certain benefit for the patient, after having taken into account a balance of earnings and losses involved in all parts of the care process" Donabedian (1980), also states that: "Medical care is given as the treatment 
provided by a health professional to a clearly established episode of illness..." (Donabedian; 1969. p. 8). This definition is maintained until today, as a pillar for Quality in Medical Care, which serves as a basis to achieve in students, the necessary awareness, to go out to Society as Professional Doctors interested in offering good Quality in Medical Services. and concerned about the welfare of patients. And when we reinforce this from the Bioethical point of view, we add the value of prevention, together with promotion, where the proverb is true: - Seeing later is not worth it, what is worth is seeing before and being prepared. Ensuring this a higher quality of care, since there is a medical thought in anticipating that the individual becomes ill, which is one of the main objectives of an Era in Public Health Medicine. Supporting the good use of technical scientific advances.

Although measuring the Quality of Health Services has always been a very complex issue, as well as ensuring it in all aspects that influence Health Care. Providing high Quality and Efficiency in Medical Care has been and is one of the fundamental purposes of the National Health System. After several investigations and observational studies, both from the point of view as a Physician and as a Professor of Medicine, certain aspects can be defined that are essential in the action and knowledge of the Graduated Physician in his Link with Society, manifested in the beginning. in your Rural Service. Quality will be defined by various aspects, among which can be listed:

- Proper management of medical knowledge and skills allowing you to make timely decisions and offer quality service.

- An adequate presence of the doctor, kindness, clothing, diction, empathy, eye contact, tone of voice and clear language (do not use technical terms that the patient often does not understand and makes him feel bad or leave with doubts).

- Generate trust in the Patient towards the Physician and the Health Center, mainly through honesty, knowledge, and dignity.

- Adequate treatment of the patient (Respect, direct contact), achieving correct communication and understanding of their needs.

- A comprehensive medical consultation, which involves all the steps (anamnesis, physical examination) for a correct diagnosis, which will allow making the right decisions and thus safeguard and improve the patient's quality of life and avoid complications.

- Respect for the dignity of patients.

- Guarantee the correct functioning of the consultations, respect of schedules and times, quality of the establishments and attention of all the personnel, as well as the conditions of the place where the consultations are offered, the suitability of the instruments, equipment and techniques used.

- Promote the safety of both the patient and the medical staff.

- The patient must be free of doubts, always explain and satisfy their needs, in case their use requires complementary tests.

- Use informed consent, whenever the situation warrants it.

- Establish a reasonable and fair cost-benefit ratio. Fair payment of health care to patients.

- Effectiveness and prompt attention. Both the Physician and the rest of the Health Center and/or Hospital staff must be receptive and ready to provide a timely service, avoiding damage and always applying the principle of 
Beneficence and Non-Maleficence. Functioning as an efficient, dedicated, and organized team.

- The patient's privacy and confidentiality must be guaranteed, whenever social conditions allow it; and when it does not represent a risk for a larger population or harm to third parties.

- The doctor must always be responsible, even if a Medical Error is committed, it is also essential that all health personnel know in detail all the problems related to them and their possible causes and consequences, as well as all legal and moral responsibility That this entails.

When medical practice is carried out, we often find ourselves in situations where decisions must be made, on difficult occasions, there is obviously a correct decision and one or more incorrect decisions, and then normally we will make the correct decision, otherwise it would surely represent an error. The Physician with all his knowledge must be able to face ethical dilemmas where his medical empowerment and his essential elements of Bioethics will allow him a predictive, timely diagnosis that supports and favours Quality in Medical Care, as a felt need of the population.

With this analysis of the doctor's behaviour in his Doctor-Patient relationship, the aim is to achieve optimal health care, allowing a considerable improvement in the population's health conditions, providing efficient, accurate services that provide patient safety. Always offering an honourable and fair treatment applying the principle of Beneficence and also that of non-Maleficence, where the doctor must watch over all things for the Well-being of the Patient, and that is something that students must be clear about from the Academy and its way to apply it in their confrontation with professional life.

It is also essential to assess patient satisfaction as a key point to establish the results of the Quality of Care in the Doctor-Patient Relationship. This concept still persists today, which was introduced more than 40 years ago by Donabedian, and which is a key point for the organization of processes and for the design of strategies focused on improving the quality of services. Where emphasis is placed on the need to satisfy both the needs and expectations of patients, considering this a key indicator for the quality of the medical service provided, understood from various variables such as trust, professional competence, comfort, efficiency, objectivity, relevance, treatment and functioning of the health system in general.

It is very important that the patient feels satisfied with the Care, but it is also necessary to satisfy the real (felt) need of the patient. These needs can be highlighted from the following points of view, which the doctor will discover as he gets to know the Patient and his Situation, through a good medical interview and his corresponding physical examination. That they guarantee less damage, always considering the collateral effects of the medicines in the treatments, as a consequence of the medical care process.

- The doctor must manage to cure diseases that are likely to be cured.

- You must achieve control of other diseases that; even if they are not curable, both communicable and non-communicable or so-called chronic, for example hypertension or diabetes; satisfactory control is achieved.

- It must guarantee a considerable improvement in conditions, such as chronic renal failure, in which it is sometimes not feasible to obtain permanent or absolute control of the same, thus avoiding progressive deterioration, until a permanent solution is achieved., such as a transplant or another. 
- Seek an improvement in the symptoms of some terminal illnesses, providing comfort, accompaniment, humanism and dying with dignity.

- The doctor at all times must give moral, social and physical support to the patient and their families, mainly in cases where, despite the correct efforts, the results obtained in terms of health have not been the most desired.

The evaluation of the services by Qualified Committees is essential to know the opinion of the patients. Patient satisfaction can be evaluated through surveys in order to know the patient's opinion about the service obtained and have a clearer idea of the points that must be improved to guarantee a Quality of Services. In addition to studying the opinion of the Doctors and thus knowing what could work better within the consultations. The fact of having an updated algorithm of the most effective procedure, demonstrating professional competence, speed, and ability in the identification of symptoms and in the appropriation of timely treatment, in excellent teamwork; would guarantee real Quality in the Medical Service.

Never forget the treatment and the doctor-patient relationship, which is increasingly lost with the misuse of technologies that sometimes the doctor's work is robotized and the interaction with the patient is lost, and it is more an interaction with the computer. For a good quality of care, certain requirements must be met, where even if there is not much access to resources, when the knowledge and treatment of the doctor prevails, the Quality of the service improves.

Although we cannot address the Quality of Service only as the Doctor-Patient Relationship, as it is an extremely complex concept and of great importance at all levels and in the functioning of Health Institutions. This is a key point that must be instilled and demonstrated to our students in order to apply it precisely and essential when they are doctors in their social work in the Community, constituting the cornerstone to arrive at a health thinking, and fulfil the purpose of preventing disease. disease or its complications. Always putting the principles of Respect, Beneficence, Non-Maleficence and Justice as a Bioethical paradigm in Quality care.

The Quality of the Services must be measured and applied in certain fundamental points such as: Reliability, Respect, Responsiveness, Professional Competence, Teamwork, Accessibility, Justice, Courtesy and Kindness, Communication, Credibility, Security and the power and knowledge Understanding and Knowing the patient, accompanying him until his last consequences of life.

\section{MATERIALS AND METHODS}

Our research is observational and qualitative, based on an exhaustive bibliographical review and on our experience as Physicians, as Professors of Medicine and Master in Bioethics. A prospective cross-sectional descriptive study was carried out with a retrospective description in order to arrive at the guide or action protocol. Where a random stratified sampling was made that yields information about the graduates and the application of the Quality of Services. A sample of 450 graduates is taken from a population of 600 graduates. 450 graduates are taken for the study because, due to exclusion criteria, all those graduates who could not attend the rural school for various reasons had to be discarded.

\section{Inclusion Criteria Exclusion Criteria}

All those graduates who did a rural service. All those graduates who did not do the rural service for various reasons such as: Family situations, Social and/or Economic situations 


\section{RESULTS}

A guide or protocol is proposed to follow that serves as a key point to achieve Quality Care in Health Services based on the Universal Principles of Bioethics, where each and every one of these aspects must be met to guarantee a Quality of excellence. which is the goal for which this research has been developed.

\section{PROPOSED GUIDE}

- Proper management of medical knowledge and skills allowing you to make timely decisions and offer quality service.

- An appropriate presence of the doctor, kindness, dress, diction, empathy, eye contact, tone of voice and clear language (do not use technical terms that the patient often does not understand and makes him feel bad or leave with doubts).

- Generate trust in the Patient towards the Physician and the Health Center, mainly through honesty, knowledge, and dignity.

- Adequate treatment of the patient (Respect, direct contact), achieving correct communication and understanding of their needs.

- A comprehensive medical consultation, which involves all the steps (anamnesis, physical examination) for a correct diagnosis, which will allow making the right decisions and thus save and improve the quality of life of the patient and avoid complications.

- Respect for the dignity of patients.

- Guarantee the correct functioning of the consultations, respect of schedules and times, quality of the establishments and attention of all the personnel, as well as the conditions of the place where the consultations are offered, the suitability of the instruments, equipment and techniques used.

- Promote the safety of both the patient and the medical staff.

- The patient must be free of doubts, always explain and satisfy their needs, in case their use requires complementary tests.

- Use informed consent, whenever the situation warrants it.

- Establish a reasonable and fair cost-benefit ratio. Fair payment of health care to patients.

- Effectiveness and prompt attention. Both the Physician and the rest of the Health Center and/or Hospital staff must be receptive and ready to provide a timely service, avoiding damage and always applying the principle of Beneficence and Non-Maleficence. Functioning as an efficient, dedicated, and organized team.

- The privacy and confidentiality of the patient must be guaranteed, whenever social conditions allow it; and when it does not represent a risk for a larger population or harm to third parties.

- The doctor must always be responsible, even if a Medical Error is committed, it is also essential that all health personnel know in detail all the problems related to them and their possible causes and consequences, as well as all legal and moral responsibility That this entails. 


\section{DISCUSSION}

Categorizing Quality is very difficult, and even more so when we are talking about a multidimensional perspective such as Bioethics. It could even be a scientifictechnical-moral quality, which makes the best of the human essence prevail. In medicine, to speak of quality is to speak of a discipline of excellence, of obtaining the best results in the face of a diagnosis, a specific technique, and even a treatment, and this doubles when we integrate Health and Education, which is a dialectical and basic pair to fulfil these requirements. However, the work in these two categories lead to continuous improvement and always in search of improvement, so our study has and will have a systematic order for the proper functioning of health services, which are based on a Bioethics where related the proposal of Peter Kemp in Europe, taking into account the principles of Autonomy, Dignity, Integrity, Beneficence, NonMaleficence, Justice and Vulnerability: with Quality in Medical Services. Promoting the elaboration of a Guide or Instrument to achieve the perception and fulfilment of Quality, from the Bioethical point of view in our graduates.

The improvement in medical care is favoured by a very good doctor-patient relationship, since it is one of the prioritized objectives of a hospital or Health Service.

The fact of having a health thinking (Bioethist), present in our graduates, would allow us to avoid not only diseases, but also the disability or invalidity of the population. A tool for the health professional is the application of action protocols and failure to fully comply with these protocols could lead to medical error, negligence and iatrogenesis.

Quality studies have been carried out in the world taking into account attributes such as patient satisfaction, Scientific-Technical quality and also in the doctor-patient relationship, and what we agree on is that it is an instrument of scientific value that represents compliance with the principles Universals of Bioethics, where not only the biological aspect of the human being is evidenced, but also interprets the fundamental methodological problem of Medical Sciences. Which is precisely the relationship between the Biological and the Social.

The graduate of the University of Guayaquil, in Medical Sciences must constitute, applying this instrument, a professional of excellence for the service of the community and an active protagonist for the formation of new generations of professionals, according to the contemporary problems that we live, and who know how to face these ethical dilemmas with knowledge, justice, honesty and values.

\section{CONCLUSIONS}

Quality in Medical Care is achieved when the Universal Principles of Bioethics are known and applied.

The Quality of Medical Attention has as its cornerstone an excellent DoctorPatient relationship.

The conception of the Graduate of the University of Guayaquil, in the Medicine career must necessarily make the Bioethist guide or instrument proposed in this investigation tangible.

Faced with the ethical dilemmas of contemporary times, the empowerment of Bioethics in the graduate responds to the continuous improvement of Quality in Health Services. 
This guide seeks to respond to the requirements that Graduated Physicians must apply for Quality Care.

\section{RECOMMENDATIONS}

- It is necessary to work, in the early training of students, in the Academy, these basic concepts of Bioethics to achieve Quality in Medical Care.

- Evaluate the effectiveness of the proposed Guide in other investigations.

- Extend this guide developed for the Medical Career to the entire Faculty of Medical Sciences of the University of Guayaquil.

- Provide interdisciplinary knowledge through a master's degree in Bioethics, which guarantees efficient teamwork and raises the Quality of the Health Service.

- Promote this knowledge and this guide to other Faculties and Universities of the Country.

"Nothing has as much power to expand the mind as the ability to systematically and realistically investigate everything that is susceptible to observation in life".

Marcus Aurelius

\section{REFERENCES}

Aguirre-Gas, Héctor \& Zavala-Villavicencio, Jesús \& Hernández-Torres, Francisco \& Fajardo Dolci, German. (2010). Quality of medical care and patient surgical safety: Medical error, malpractice andprofessional liability. Cirugia y cirujanos. 78. 456-62. https://www.medigraphic.com/pdfs/circir/cc2010/cc105o.pdf

Alberti, K. G. M. M. (2001). Medical errors: à common problem. BMJ, 322(7285), 501-502. https://doi.org/10.1136/bmj.322.7285.501

Andino Acosta, C. A. (2015). Bioética y humanización de los servicios asistenciales en la salud. Revista Colombiana de Bioética, 10(1), 38. https://doi.org/10.18270/rcb.v10i1.684

Andrés, J.M., Maseres, J.B., \& Castro, M.T. (2004). Efectos adverses en el siglo. XXI.

(8.a ed.) La epidemia silenciosa. Monografías Humanitas,

Barach, P. (2000). Reporting and preventing medical mishaps: lessons from nonmedical near miss reporting systems. BMJ, 320(7237), 759-763. https://doi.org/10.1136/bmj.320.7237.759

Carvallo V., A. (2001). Ethical reflections on errors in medicine. Revista médica de Chile, 129(12), 1400-1489. https://doi.org/10.4067/S003498872001001200015

D'Empaire, G. (2010). Health care quality and ethical principles. Acta Bioethica, 16(2). $\quad$ Retrieved from https://actabioethica.uchile.cl/index.php/AB/article/view/15613/16085

D’Empaire, G., \& DEmpaire, M. E. (2003). La ética de la indicación médica y la medicina basada en la evidencia. Clín. méd. HCC, 30-36.

De Los Ríos Castillo, José Lauro, \& Ávila Rojas, Teresa Luzeldy (2004). Algunas consideraciones en el análisis del concepto: satisfacción del paciente. Investigación y Educación en Enfermería, XXII (2),128-137. [fecha de Consulta 28 de Febrero de 2022]. ISSN : 0120-5307. Disponible en :

https://www.redalyc.org/articulo.oa?id=105216892010 
Diaz - DOCTORATE SCIENCE AND ENGINEERING HEALTH SYSTEM IN.pdf [Online].

[cited $2021 \quad$ Sep 1$]$. Available at : https://www.aiu.edu/publications/student/spanish/180207/PDF/HECTOR\%20EDUARD0\%20GONZALEZ\%20DIAZ.pdf

Domínguez Márquez, O., \& Manrique Nava, C. (2011). Bioethics in primary health care And public health quality. Acta Bioethica, 17(1). Retrieved from https://actabioethica.uchile.cl/index.php/AB/article/view/15673/16146

Donabedian, A. (1986). Quality Assurance in Our Health Care System (1.a ed., Vol. 1). Quality Assurance and Utilization Review. https://doi.org/10.1177/0885713X8600100104

Donabedian, A. (1980). The Definition of Quality and Approaches to Its Assessment (Vol. 1). Amsterdam University Press.

Escobar López, M. T. (2013). Bioética: nuevas tendencias. Revista Latinoamericana de Bioética, 13(24-1), 6. https://doi.org/10.18359/rlbi.565

Fariño Cortez, J. E., Vera-Lorenti, F. E., Alicia Gabriela, C.-M., Velasco Donoso, A. P., Llimaico Noriega, M. de J., \& Saldarriaga Jiménez, D. G. (2021). Satisfacción de usuarios y calidad de atención en unidades primarias de Salud de Milagro. Revista Ecuatoriana De Ciencia Tecnología E Innovación En Salud Pública, 2(2). Recuperado a partir de https://www.inspilip.gob.ec/index.php/inspi/article/view/97

Figueroa C, Gustavo. (2007). Como arqueros al blanco : Estudios de bioética. Revista $\begin{array}{llll}\text { chilena de neuro-psiquiatría, } & \text { 45(1), }\end{array}$ https://dx.doi.org/10.4067/S0717-92272007000100014

Guillén, D. G. (2008). Fundamentos de bioética. Triacastela.

Institute of Medicine (US) Committee to Design a Strategy for Quality Review and Assurance in Medicare, \& Lohr, K. N. (Eds.). (1990). Medicare : A Strategy for Quality Assurance. National Academies Press (US).

Leape, L. L. (1994). Error in Medicine. JAMA : The Journal of the American Medical Association, 272(23), 1851. https://doi.org/10.1001/jama.1994.03520230061039

Mgtr. Cecilia Patricia León Vega, Directora Nacional De Calidad De Los Servicios De Salud. (2021). Dirección Nacional de Calidad de los Servicios de Salud Ministerio de Salud Pública. https://www.salud.gob.ec/direccion-nacionalde-calidad-de-los-servicios-de-salud/

Makary, M. A., \& Daniel, M. (2016). Medical error-the third leading cause of death in the US. BMJ, i2139. https://doi.org/10.1136/bmj.i2139

Massip Pérez, Coralia, Ortiz Reyes, Rosa María, Llantá Abreu, María del Carmen, Peña Fortes, Madai, \& Infante Ochoa, Idalmis. (2008). La evaluación de la satisfacción en salud: un reto a la calidad. Revista Cubana de Salud Pública, 34(4) Recuperado en 28 de febrero de 2022, de http://scielo.sld.cu/scielo.php?script=sci_arttext\&pid=S0864$34662008000400013 \& \operatorname{lng}=\mathrm{es} \& \operatorname{tln} \mathrm{n}=\mathrm{es}$

Montiel, G. Q. (2018, 21 septiembre). LA MALA CALIDAD DE LA ATENCIÓN DE SALUD MATA. Ecuador | Noti-America.com. https://notiamerica.com/site/ecuador/2018/09/21/la-mala-calidad-de-la-atencionde-salud-mata/

Pérez, M. C. (2008). La evaluación de la satisfacción en salud: un reto a la calidad. Revista Cubana de Salud Pública. 
http://scielo.sld.cu/scielo.php?script=sci_arttext\&pid=S0864-

34662008000400013\&lng=es\&tlng=es

Pellegrino E. D. (1990). La relación entre la autonomía y la integridad en la ética médica [Relationship between autonomy and integrity in medical ethics]. Boletin de la Oficina Sanitaria Panamericana. Pan American Sanitary Bureau, 108(5-6), 379-390

Romero Chávez, E., Contreras Estrada, D., \& Cantú Quintanilla, G. (2019). Quality of medical care from an bioethical point of view in an ophthalmological hospital in Mexico City. Acta Bioethica, 25(2), 235-242. Retrieved from https://revistas.uchile.cl/index.php/AB/article/view/54812/60051

Sánchez, G. M. E. M. (2019, 4 octubre). Satisfacción del paciente hospitalizado y aplicación de los principios bioéticos en el cuidado de enfermería, del Servicio de Cirugía del Hospital Belén de Trujillo, 2019. Universidad Cèsar Vallejo - $\quad$ Repositorio Digital Institucional. https://repositorio.ucv.edu.pe/handle/20.500.12692/36792

Spanish Royal Academy, \& Española, R. A. D. L. L. (2002). Diccionario de la Lengua Espanola / Dictionary of the Spanish Language (23.a ed.). Planeta Pub Corp. https://dle.rae.es 